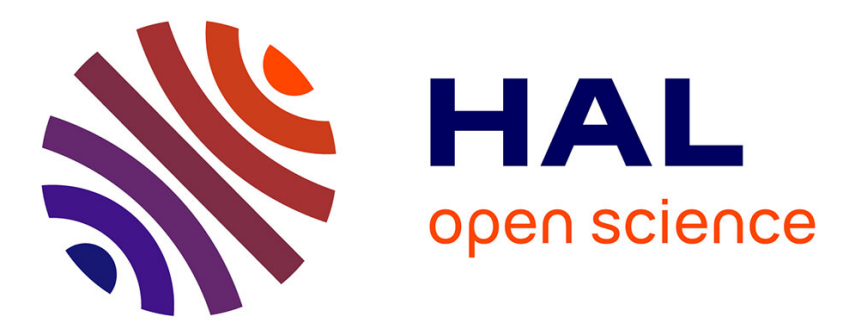

\title{
Modeling oxygen and water flows in peat substrate with root uptakes
}

\author{
Rémi Naasz, Jean-Charles Michel, Sylvain Charpentier
}

\section{To cite this version:}

Rémi Naasz, Jean-Charles Michel, Sylvain Charpentier. Modeling oxygen and water flows in peat substrate with root uptakes. Proceedings of the International Symposium on Growing Media, Sep 2005, Angers (FR), France. pp.191-197. hal-00729768

\section{HAL Id: hal-00729768}

\section{https://institut-agro-rennes-angers.hal.science/hal-00729768}

Submitted on 5 Apr 2013

HAL is a multi-disciplinary open access archive for the deposit and dissemination of scientific research documents, whether they are published or not. The documents may come from teaching and research institutions in France or abroad, or from public or private research centers.
L'archive ouverte pluridisciplinaire HAL, est destinée au dépôt et à la diffusion de documents scientifiques de niveau recherche, publiés ou non, émanant des établissements d'enseignement et de recherche français ou étrangers, des laboratoires publics ou privés. 


\title{
Modeling Oxygen and Water Flows in Peat Substrate with Root Uptakes
}

\author{
R. Naasz, J.-C. Michel and S. Charpentier \\ UMR A_462 'SAGAH' INRA/INH/University of Angers \\ Agronomic Sciences Applied to Horticulture \\ Angers \\ France
}

Keywords: peat, simulation, substrate-plant system, water and oxygen availability, hydraulic properties, soilless culture

\begin{abstract}
Distribution and movement of liquids and gases in growing media present high specificity compared to in situ soil. This is due to the limited volume of susbtrate in which water and oxygen availability highly fluctuate over a short period of time (a few hours), and could rapidly lead to stress conditions. In order to improve our knowledge of the substrate-plant system, we first precisely characterized all transfer properties of a peat substrate (water retention, hydraulic conductivity, oxygen diffusivity and volume variation), during a drying-wetting cycle. All these characteristics were integrated into a one-dimensional transfer coupled model of water and oxygen, combining a macroscopic approach, Richards' equation, with a root function (water and oxygen uptakes). By imposing conditions close to those found in soilless production, our model allow us to follow the evolution of hydrodynamic and structural parameters of the substrate-plant system on a one-day time scale. If one replaces in the "not-limiting" range of water content, corresponding to a high hydraulic conductivity $\left(\theta>0.45 \mathrm{~m}^{3} \mathrm{~m}^{-3}\right)$ and a high oxygen diffusivity $\left(\theta<0.70 \mathrm{~m}^{3} \mathrm{~m}^{-3}\right)$, our model underline that little changes in the initial conditions involve rapid decrease of water and oxygen content in the susbtrate. Consequently, it could lead to important and sustained water and oxygen stress conditions in the root vicinity.
\end{abstract}

\section{INTRODUCTION}

In soilless production, optimal growth conditions are difficult to obtain because of the high variability of gas, water and solute distribution into the whole substrate during the day (Brun et al., 2004; Charpentier et al., 2004) but also during the different growing season. Water and oxygen content and movement in the porous media, root uptakes could therefore highly fluctuate depending on: (1) the substrates used (related to their physical, chemical, hydraulic and structural properties) and/or (2) the species and the vegetative stages of the plant considered.

Consequently, the nutritive conditions in the root zone could rapidly become different from the real and instantaneous needs of the plants. Effective management of fertigation is therefore delicate and it is essential to find a compromise, for a given substrate-plant system, allowing to avoid water, oxygen and mineral excesses and deficiencies during the whole growing season. In order to better match supply to plant needs, taking into account the environmental constraints limiting pollutant leaching, it is still necessary to improve our understanding of matter transfer at the substrate-root interface.

By its integrating aspect, a modeling approach of the substrate-plant system is needed. Indeed, it is the whole of the interactions (physical, biological, physico-chemical, structural, etc.) taking place in this system that have to be considered, rather than isolated effects from each characteristics. Insofar as mechanistic models try to formalize the maximum processes they are adequate tools for this kind of research. In a general way, these models solve Richards' equation for water flow and the convective-diffusive equation for gas flow. Nevertheless, modeling approach could not be lead without a preliminary and precise study of all properties taking part in the processes of water and oxygen transfer into the substrate. 
However, until now, most studies dealing with the physical properties of substrates have only attempted to characterize water and gas distribution related to water potential (de Boodt and Verdonck, 1972; Rivière et al., 1990; Nowak and Strojny, 2004), disregarding their transfer properties and their availability to the plant.

This is why, we first adopted an experimental approach to better understand the hydrodynamic behaviour of peat (main reference substrate in horticulture) during a drying/wetting cycle. In order to represent the effect, of all properties beforehand defined, on oxygen and water availability related to plant needs, we secondly embed these properties into a one-dimensional transfer coupled model of water and oxygen in the root vicinity and on a one-day time scale.

\section{MATERIALS AND METHODS}

Weakly decomposed Sphagnum peat was chosen as model in our study. Indeed, Sphagnum peat is internationally considered as the main reference substrate in horticultural production (in terms of quality and quantity). The finest fractions of this substrate were used for this study (particle size range of $0-5 \mathrm{~mm}$ ). The main characteristics of peat were presented in Table 1. Since the physical properties of organic substrates are largely influenced by preparation and more precisely by the packing of materials, peat was prepared according to the European standardised procedure NF EN 13041 (2000) to avoid manual packing.

\section{Water and Oxygen Properties Measurements}

For hydraulic measurements, we developed in the laboratory a transient method during desiccation and infiltration experiments as well (Naasz et al., 2005). This experimental device was coupled with an automatic system of image acquisition (Michel et al., 2004) in order to measure the substrate volume variation (shrinkage/swelling). Experiments were carried out on transparent columns PVC $(10 \mathrm{~cm}$ in diameter and $12 \mathrm{~cm}$ high; $\mathrm{V}=942 \mathrm{~cm}^{3}$ ) filled with peat. The whole set of photographs obtained with a digital camera was then analysed using a data-processing tool developed with the Matlab $\mathbb{B}$ software. These experimental procedures made it possible to establish water retention and shrinkage/swelling curves, and to directly calculate hydraulic conductivity by the instantaneous profile method (Green et al., 1986).

Oxygen diffusivity measurements were estimated with the transient method developed by Bakker and Hidding (1970), adapted on peat substrate by Gislerod (1982). Experimental device consists in measuring the oxygen content increase (with an oxygen probe) according to time in a diffusion chamber beforehand filled with nitrogen. Diffusion chamber is connected to the atmosphere via a sample of substrate, in which water potential was fixed at 10 different values $(-0,5 \mathrm{kPa}$ to $-316 \mathrm{kPa})$ during a drying/wetting cycle. Oxygen diffusivity is calculated by using a simplified analytical solution of the general equation of diffusion of gases (second Fick's law).

\section{Modeling Availability of Water and Oxygen}

Hydrodynamic (water retention, hydraulic conductivity and oxygen diffusivity curves) and structural characteristics of peat (shrinkage/swelling curves) were integrated into a one-dimensional transfer coupled model of water and oxygen in an isotropic, homogeneous and deformable porous media (Naasz, 2005). A macroscopic approach, Richards' equation (Richards, 1931) for water flow and the convective-diffusive equation for gas flow, was combined with a sink term (a sink surface) representing the whole root system. Water and oxygen uptakes by root were considered homogeneous and isotropic on the entire sink surface. Taking all requirements beforehand mentioned into account, transfer equations were numerically resolved using an explicite finite difference method. The spatial and temporal discretization was realized after a consistent analysis of the different dimensions of the system. 


\section{RESULTS AND DISCUSSION}

\section{Physical Properties}

Our results concerning hydraulic properties (Fig. 1a), like those obtained by da Silva et al. (1993), show a sharp decrease in hydraulic conductivity (about four orders of magnitude) occurring on very small range of water content (between 0.45 and $0.35 \mathrm{~m}^{3}$ $\mathrm{m}^{-3}$ ). Moreover, this sharp decrease appears well before (at $-5 \mathrm{kPa}$ ) the semi-empirical threshold of $-10 \mathrm{kPa}$ established by de Boodt and Verdonck (1972). In a similar way, our results on gas transfer (oxygen diffusivity, Fig. 1b), like those obtained Caron and Nkongolo (2004) on peat materials also reveal important decrease in oxygen diffusivity, observed around $-2 \mathrm{kPa}$ (corresponding to $0.16 \mathrm{~m}^{3} \mathrm{~m}^{-3}$ of air content). Shrink/swell curves obtained on this weakly decomposed peat, during the drying/wetting cycle, also show a shrinkage and swelling close to $20 \%$ for a range of water potentials varying between 0 and $-20 \mathrm{kPa}$ (Table 2).

The overall results tend to define ranges of water and air content for which oxygen and water flows become very low and could be therefore potentially limiting for the root functioning (Fig. 2). Conversely, it remains to be known if these apparently optimal ranges of water contents, for high water and air transfer in the substrate, are in adequacy with the physiological needs (hydrous and gaseous) for the plant.

\section{Simulation}

The modeling approach could give answers to the beforehand interrogation. Thus, if one replaces in the "not-limiting" range of water content considered above $\left(\theta_{\text {initial }}=\right.$ $0.60 \mathrm{~m}^{3} \mathrm{~m}^{-3}$ ), corresponding to simultaneous high hydraulic conductivity and oxygen diffusivity, our model underline different key point during the day of simulation $(800 \mathrm{mn})$ (Naasz, 2005):

(1) water content near the root considerably decrease to reach very low water availability, producing important and sustained water stress conditions from half day of simulation ( $\sim 400$ minutes) until the end of the day (Fig. 3). Average water content, in the whole substrate volume, slightly decrease.

(2) simultaneously, oxygen content near the root also considerably diminish, producing moderate but sustained oxygen stress conditions from half day of simulation until the end of the day (Fig. 4).

More, for this fine peat substrate and whatever the initial water content considered, the overall simulation results show that it is impossible to maintain during a one-day time scale, at the same time, high water and oxygen availability for the root (Fig. 5). Anoxic conditions appear from saturation until $0.55 \mathrm{~m}^{3} \mathrm{~m}^{-3}$ of water content, and hydric stress conditions appear from $0.65 \mathrm{~m}^{3} \mathrm{~m}^{-3}$ of water content to lower hydric state.

\section{CONCLUSIONS}

Our experimental approach allow us to define water content ranges for which transfer characteristics (oxygen and water flows) become very low and could be therefore potentially limiting for the root functioning. By imposing conditions close to those found in soilless production, our model allow us to follow the evolution of water and oxygen availability in the root environment and on a one-day time scale. If one replaces in the "not-limiting" range of water content, corresponding to high hydraulic conductivity and high oxygen diffusivity, the 1-D model underlines and confirms that it is impossible to maintain, at the same time, high water and oxygen availability to the root. Consequently, it could lead to important and sustained water and oxygen stress conditions at the peatsubstrate interface. These first results of simulation are very encouraging. Its must be now validated experimentally with greenhouse tests.

\section{Literature Cited}

Bakker, J.W. and Hidding, A.P. 1970. Influence of soil structure and air content on gas diffusion in soil. Neth. J. Agr. Sci. 18:37-48. 
Brun, R., Barthelemy, L., Longuenesse, J.J. and Reich, P. 2004. Distribution of Water in Rockwool Slabs. Greensys 2004 Conference. Sustainable Greenhouse Systems. Leuven, Belgium 12-16 September. p.123.

Caron, J. and Nkongolo, N.V.K. 2004. Assessing gas diffusion coefficients in growing media from in situ water flow storage measurements. Vadose Zone J. 3:300-311.

Charpentier, S., Guérin, V., Morel, P. and Tawegoum, R. 2004. Measuring Water Content and Electrical Conductivity in Subtrates with TDR (Time Domain Reflectometry). Acta Hort. 644:283-290.

da Silva, F.F., Wallach, R. and Chen, Y. 1993. Hydraulic properties of sphagnum peat moss and tuff (scoria) and their potential effects on air availability. Plant Soil 154:119-126.

de Boodt, F. and Verdonck, O. 1972. The physical properties of the substrates in horticulture. Acta Hort. 26:37-44.

Gislerod, H.R. 1982. Physical conditions of propagation media and their influence on the rooting of cuttings: I. Air content and oxygen diffusion at different moisture tensions. Plant Soil 69:445-456.

Green, R.E., Ahuja, L.R. and Chong, S.K. 1986. Hydraulic Conductivity, Diffusivity and Sorptivity of Unsaturated Soils. p.771-798. In: A. Klute (ed.), Methods of soil Analysis, Part 1. Physical and mineralogical Methods, American Society of Agronomy, Madison.

Michel, J.-C., Naasz, R. and Montgermont, N. 2004. A tool for measuring the shrink/swell phenomena of peat growing media by image analysis. Proc. $12^{\text {th }}$ International Peat Congress. Wise use of peatlands. Tampere, Finland 6-11 June. p.321-325.

Naasz, R. 2005. Flux couplés d'eau et d'oxygène dans les supports de culture organiques : analyse et modélisation. Thèse de doctorat, Université d'Angers.

Naasz, R., Michel, J.-C. and Charpentier, S. 2005. Measuring Hysteretic Hydraulic Properties of Peat and Pine Bark Using a Transient Method. Soil Sci. Soc. Am. J. 69:13-22.

Nowak, J.S. and Strojny, Z. 2004. Changes in physical properties of peat-based substrates during cultivation period of gerbera. Acta Hort. 644:319-323.

Richards, L.A. 1931. Capillary conduction of liquids through porous mediums. Physics. 1:318-333.

Rivière, L.-M., Foucard, J.C. and Lemaire F. 1990. Irrigation of container crops according to the substrate. Sci Hortic-Amsterdam 43:339-349.

\section{$\underline{\text { Tables }}$}

Table 1. Main characteristics for the peat substrate studied. Means of four repetitions with standard deviations (numbers in parentheses).

\begin{tabular}{cccccccc}
\hline $\begin{array}{c}\text { Bulk } \\
\text { density } \\
\left(\mathrm{g} \mathrm{cm}^{-3}\right)\end{array}$ & $\begin{array}{c}\text { Particle } \\
\text { density } \\
\left(\mathrm{g} \mathrm{cm}^{-3}\right)\end{array}$ & $\begin{array}{c}\text { Organic } \\
\text { matter } \\
(\%)\end{array}$ & $\mathrm{C}$ & $\mathrm{N}$ & $\mathrm{C} / \mathrm{N}$ & $\mathrm{pH}$ & $\mathrm{CEC}$ \\
\hline 0.119 & 1.53 & 93.0 & 50.5 & 0.932 & 54.2 & 4.4 & 103.1 \\
$(0.01)$ & $(0.01)$ & $(0.04)$ & $(1.2)$ & $(0.02)$ & & $(0.04)$ & $(1.1)$ \\
\hline
\end{tabular}


Table 2. Description of the three phases observed during desiccation and rehydration of the peat sample. $\mathrm{V}_{\mathrm{V}}, \mathrm{V}_{\mathrm{S}}, \mathrm{V}_{\mathrm{W}}, \mathrm{V}_{\mathrm{A}}$ correspond to the volumes of void, solid, water and air in the substrate; $\vartheta_{\mathrm{a}}, \vartheta$ and $e$ are respectively air, water and void ratios, $\theta$ is the water content $\left(\mathrm{m}^{3} \mathrm{~m}^{-3}\right)$, and $\Phi$ is the water potential expressed in $\mathrm{kPa} . \Delta$ represents the difference for the void, water and air ratios during each step.

\begin{tabular}{|c|c|c|c|c|c|c|c|c|c|c|c|}
\hline & \multicolumn{5}{|c|}{ Desiccation } & \multicolumn{6}{|c|}{ Rehydration } \\
\hline & I & & II & & III & & III' & & II' & & I' \\
\hline$e=V_{\mathrm{v}} / V_{\mathrm{s}}$ & 15.8 & 15.7 & & 12.8 & & 12.7 & & 13.6 & & 15.6 & 15.8 \\
\hline$\Delta e$ & -0.1 & & -2.9 & & -0.1 & & +0.9 & & +2.0 & & +0.2 \\
\hline$\vartheta=V_{\mathrm{e}} / V_{\mathrm{s}}$ & 15.8 & 14.5 & & 11.4 & & 5.6 & & 11.4 & & 14.5 & 15.8 \\
\hline$\Delta \vartheta$ & -1.3 & & -3.1 & & -5.8 & & +5.8 & & +3.1 & & +1.3 \\
\hline$\vartheta_{\mathrm{a}}=V_{\mathrm{a}} / V_{\mathrm{s}}$ & 0.0 & 1.2 & & 1.4 & & 7.1 & & 2.2 & & 1.1 & 0.0 \\
\hline$\Delta \vartheta_{\mathrm{a}}$ & +1.2 & & +0.2 & & +5.7 & & -4.8 & & -1.1 & & -1.1 \\
\hline$\theta\left(\mathrm{m}^{3} \mathrm{~m}^{-3}\right)$ & 0.94 & 0.87 & & 0.78 & & 0.40 & & 0.66 & & 0.87 & 0.94 \\
\hline$\Phi(\mathrm{kPa})$ & 0 & -1 & & -2 & & -20 & & -1 & & -0.5 & 0 \\
\hline
\end{tabular}

\section{Figures}
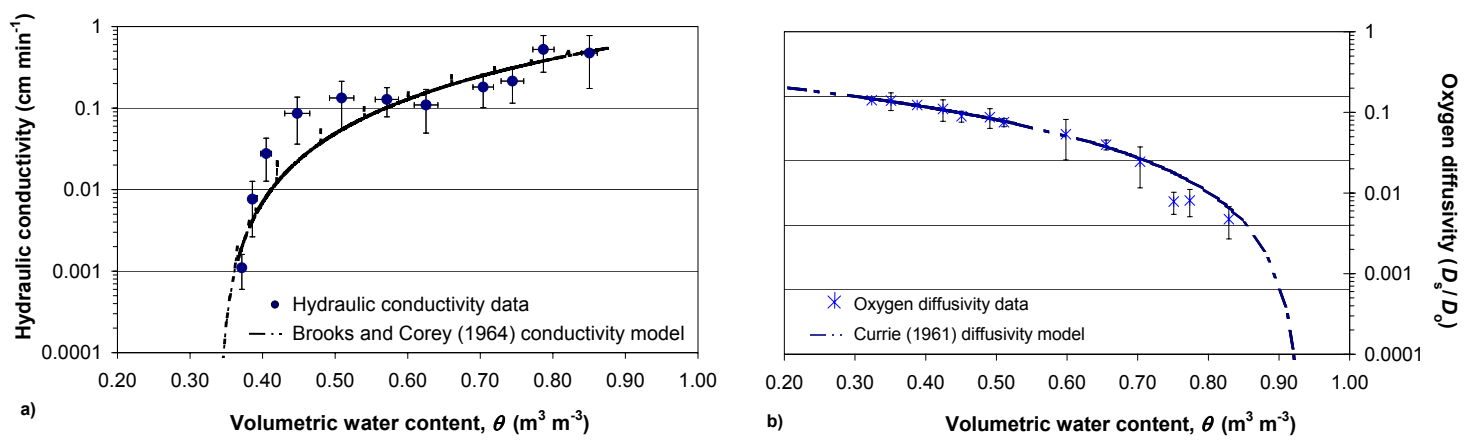

Fig. 1. Calculated (symbols) and predicted (lines) hydraulic conductivity (a) and oxygen diffusivity (b) as a function of volumetric water content for peat substrate. 


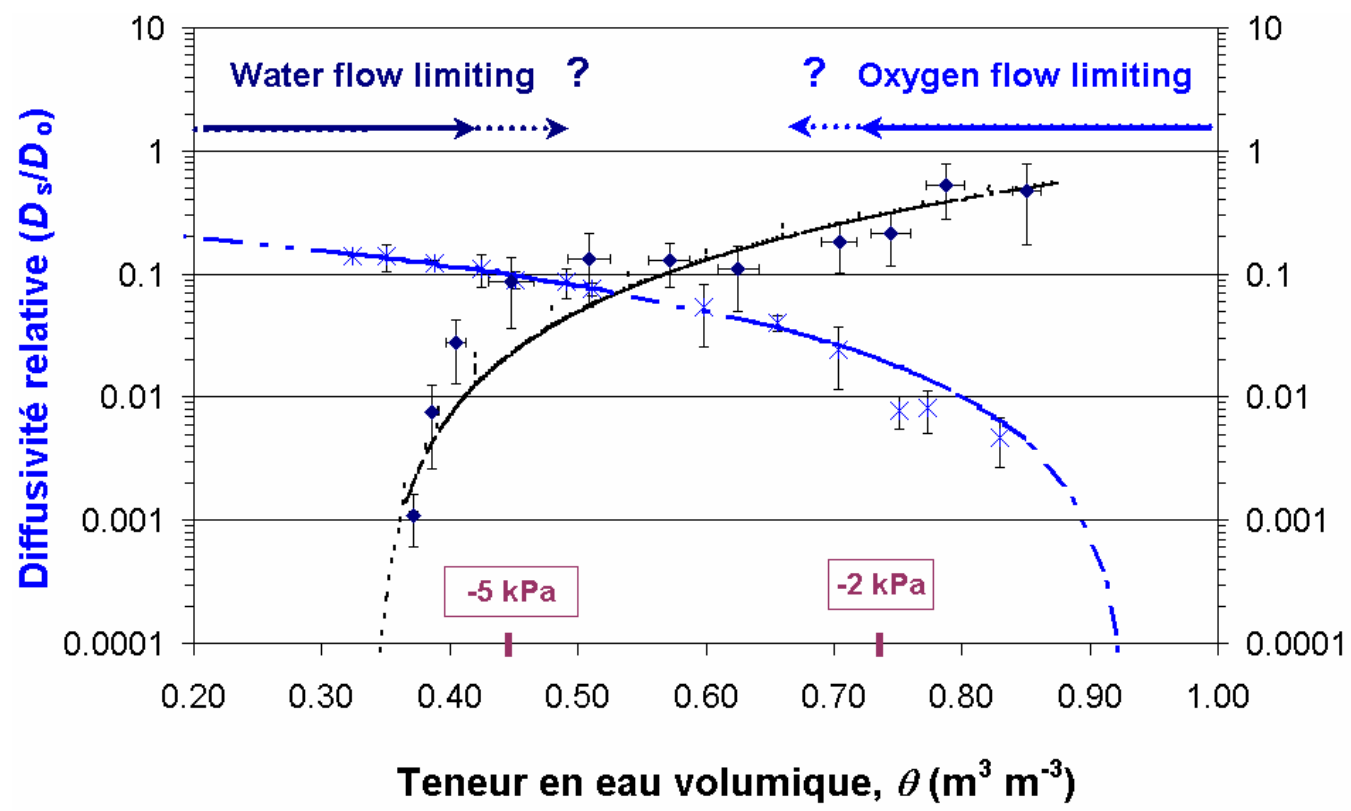

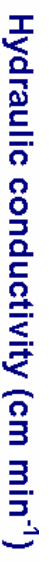

Fig. 2. Hydraulic conductivity - oxygen diffusivity relationship as a function of water content for peat substrate.

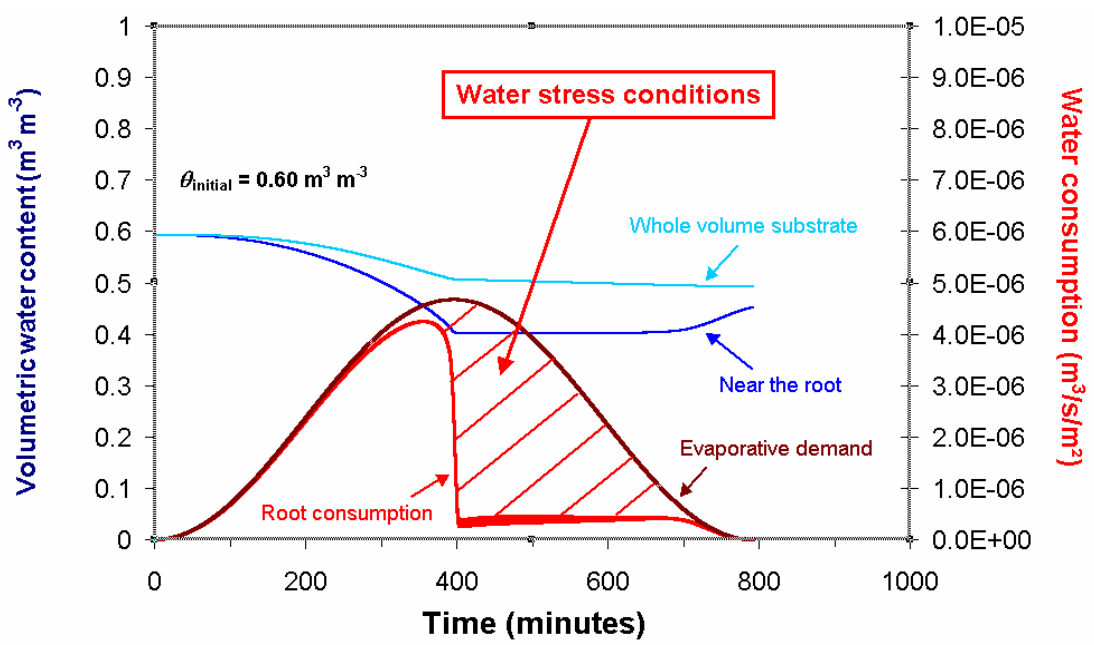

Fig. 3. Evolution of water availability and water consumption in a peat substrate $\left(\theta_{\text {initial }}=\right.$ $0.60 \mathrm{~m}^{3} \mathrm{~m}^{-3}$ ) during one day of simulation (800 minutes). 


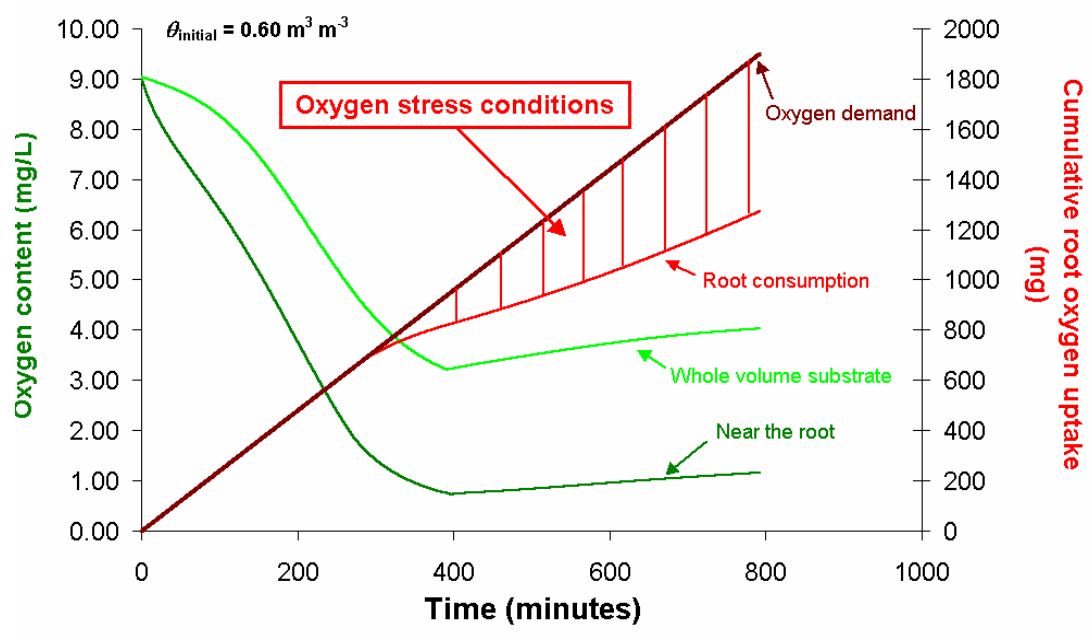

Fig. 4. Evolution of oxygen availability and oxygen consumption in a peat substrate $\left(\theta_{\text {initial }}=0.60 \mathrm{~m}^{3} \mathrm{~m}^{-3}\right)$ during one day of simulation ( 800 minutes $)$.

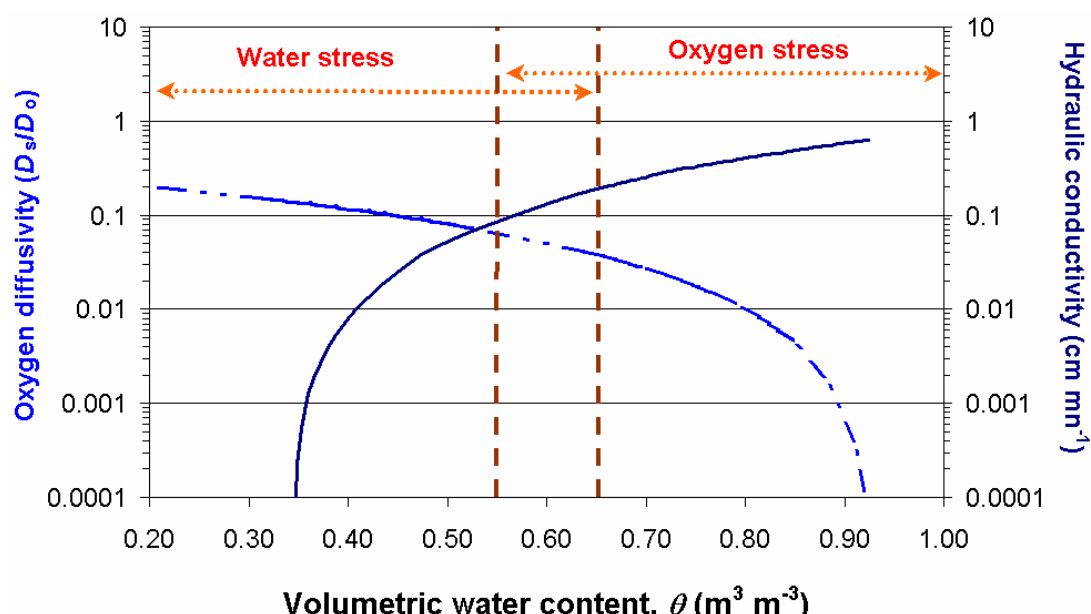

Fig. 5. Schematic representation of anoxic and water stress conditions as a function of water content for the peat substrate. 
